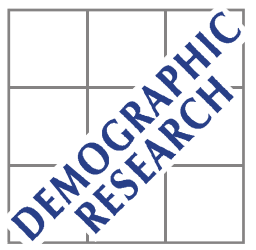

Demographic Research a free, expedited, online journal of peer-reviewed research and commentary in the population sciences published by the Max Planck Institute for Demographic Research Konrad-Zuse Str. 1, D-18057 Rostock · GERMANY www.demographic-research.org

DEMOGRAPHIC RESEARCH

VOLUME 27, ARTICLE 23, PAGES 681-704

PUBLISHED 16 NOVEMBER 2012

http://www.demographic-research.org/Volumes/Vol27/23/

DOI: 10.4054/DemRes.2012.27.23

Research Article

\title{
Whose education affects a child's nutritional status? From parents' to household's education
}

\section{Francesco Burchi}

\section{(C) 2012 Francesco Burchi.}

This open-access work is published under the terms of the Creative Commons Attribution NonCommercial License 2.0 Germany, which permits use, reproduction \& distribution in any medium for non-commercial purposes, provided the original author(s) and source are given credit.

See http:// creativecommons.org/licenses/by-nc/2.0/de/ 


\section{Table of Contents}

$\begin{array}{lll}1 & \text { Introduction } & 682\end{array}$

2 Literature review $\quad 683$

3 Methodology 686

$4 \quad$ Dataset and data description $\quad 688$

4.1 Measures of child nutrition $\quad 688$

$\begin{array}{lll}4.2 & \text { Explanatory variables } & 688\end{array}$

$\begin{array}{lll}4.3 & \text { Descriptive statistics } & 690\end{array}$

$5 \quad$ Econometric estimates 691

$\begin{array}{lll}5.1 & \text { Determinants of child height-for-age } & 691\end{array}$

5.2 Determinants of child weight-for-age $\quad 694$

5.3 Comparing results 696

6 Conclusions $\quad 697$

$7 \quad$ Acknowledgements $\quad 699$

$\begin{array}{ll}\text { References } & 700\end{array}$ 


\title{
Whose education affects a child's nutritional status? From parents' to household's education
}

\author{
Francesco Burchi ${ }^{1}$
}

\begin{abstract}

\section{BACKGROUND}

The paper engages in the ongoing debate regarding the determinants of child nutrition in developing countries and stresses the potential contribution of the education of household members other than the child's parents.
\end{abstract}

\section{OBJECTIVE}

The aim of the paper is threefold: (1) to verify whether there is evidence of the key role of parents' education for children's nutrition; (2) to explore the possible presence of the externalities generated by the literacy of household members different from the child's parents; (3) to test whether there is difference in the influence of these variables on the two indicators of child nutrition, child height-for-age and weight-for-age.

\section{METHODS}

The determinants of child nutrition were analyzed by estimating a series of econometric models through OLS regressions applied on data from the 2003 DHS survey in Mozambique. By means of seemingly unrelated regression together with formal testing we compared the impact of the covariates on the two outcomes.

\section{RESULTS}

In line with previous studies, we find that one year of mother's education increases their children's height-for-age and weight-for-age z-scores by nearly 0.025 and 0.015 . The presence of another literate household member has a significant, though limited, effect on child height while it has no influence on child weight. Lastly, there is no statistically significant difference in the effect of parents' education on the two indicators while our measure of proximate literacy has a significantly larger impact on child height.

\section{CONCLUSIONS}

These findings should orient policy-makers toward income-augmenting and educationenhancing policies: the importance of non-parents' literacy opens a further space for investment in education.

\footnotetext{
${ }^{1}$ Roma Tre University, Department of Economics. E-mail: fburchi@uniroma3.it.
} 


\section{Introduction}

This paper engages in the ongoing debate on the determinants of child malnutrition in developing countries. A vast literature has already stressed the positive role of socioeconomic factors such as household wealth and parents' education. The present paper intends to provide a further contribution to the field by: 1) extending the attention from the mother's or parents' education to the education of all the household members; and 2) separately examining the influence of different factors in improving children's chronic and acute nutritional status with special emphasis on those related to education.

With regard to the first objective, the hypothesis is that an illiterate mother (or illiterate parents) can still benefit from the ability of other household members to read and write. Most of the research has concentrated only on parents while other household members like grandparents or older brothers and sisters can be important care-takers. With regard to the second point, our specific objective is to understand if the role of household members' education and other explanatory factors changes depending on whether we focus on child height-for-age - a proxy for long-run malnutrition - or weight-for-age - an indicator that can pick up short-run malnutrition, long-run malnutrition, or a combination of both. In this paper we employ a methodology rarely used in this field to test the different effect of the determinants on the two dependent variables.

The research focuses on Mozambique due to its large deprivations in both nutritional and educational indicators. With respect to nutrition, it was estimated that nearly $45 \%$ of the total population is undernourished (Food and Agriculture Organization 2006), requiring an urgent intervention. In educational achievements, Mozambique is ranked 172 of 177 countries using the Education Index adopted by the United Nations Development Programme (2007). Moreover, the choice of country was motivated by data availability. The 2003 data from the Demographic and Health Surveys (DHS) contain a large and complete set of information on education, nutrition, and health.

The paper is structured as follows. Section two contains the literature review, section three illustrates the research methodology, section four explains the dataset and shows descriptive statistics, section five presents estimation results, and conclusions are drawn in the final part of the paper. 


\section{Literature review}

There is abundant empirical literature on the effect of a mother's or parents' schooling on children's malnutrition. Most of the results were achieved applying the following methodology. First, the broad effect of mother's schooling was estimated, controlling only for children, household, and context factors. Among these factors, biologists suggest including parents' nutritional indicators referring to the period in which the child was conceived; omitting these variables risks leading to an overestimation of the effect of mother's education on children's nutritional status (Barrera 1990). After considering this set of variables, mother's education was still a key determinant of children's nutrition. ${ }^{2}$ These results were, for example, found in Morocco for children under five years of age (Glewwe 1999) as well as in Bolivia for children under three years of age (Morales, Aguilar, and Calzadilla 2004).

Since many scholars have (rightly) argued that education could simply reflect the effect of household economic welfare on child health, most of the authors have also controlled for economic factors. The result, in many cases, is that the positive effect of mother's education still remains significantly different from zero (Strauss and Thomas 1995). There is also some empirical evidence of this relationship in Mozambique (Sahn and Alderman 1997; Garrett and Ruel 1999; Burchi 2010). In the studies conducted with 1996-1997 data, Sahn and Alderman (1997) and Garrett and Ruel (1999) concluded that the effect of mother's education is significant and independent from that of household income/wealth in the case of 0-2 year old children while non-significant for 2-5 year old children. In the first study the result is also robust to the inclusion of mother's nutrition, while such a variable was not available in the second study. The work of Burchi (2010), carried out on the basis of more recent data, has highlighted that the influence of mother's education is important for the nutritional status of preschool children, even after controlling for a large set of confounders including the mother's anthropometric status.

In the available literature on this topic, different pathways of influence have been identified to explain this robust relationship between a mother's schooling and children's nutrition. This relationship is likely to operate through a traditional economic channel because, in a functioning labor market, qualified people should obtain a better job, thus having more income to use for their children's wellbeing. Moreover, schools can be a place where students directly obtain information on nutrition and health (Alderman, Hentschel, and Sabates 2003; Webb and Block 2004). Another important channel is information acquisition: for example, literate mothers can read the instructions of medicines and understand nutritional and health information

\footnotetext{
${ }^{2}$ Due to lack of data on parents' nutrition at the time of conception or data on mother's nutrition during pregnancy, most of the authors use variables reflecting their nutrition at the time of the survey.
} 
disseminated by media like newspapers. Finally, a fundamental - but often neglected in empirical studies - pathway specifically connecting a mother's education and child nutrition is empowerment: more educated women are more self-confident and participate more in household and community decision making. Since women are usually the primary child caregivers of a family in many parts of the world and are responsible for allocating a higher share of household resources to children's' wellbeing, empowerment is likely to result in better health and nutritional status for children.

Due to the complex interaction among these factors, only few studies have attempted to empirically investigate the relative weight of each channel, leading to mixed results (Thomas, Strauss, and Henriques 1991; Webb and Block 2004; Frost, Forste, and Haas 2005; Burchi 2010).

New insights have been offered on the potential role of education in enhancing a series of socio-economic outcomes resulting from the spill-over effects of education at the household level (Basu and Foster 1998; Gibson 2001; Basu, Narayan, and Ravaillon 2001). Basu and Foster (1998) argue that the traditional way of measuring illiteracy is valid as long as literacy is needed, for example, to obtain a qualified job: in this case it is indispensable that the person herself is at least literate. When, instead, literacy is functional to obtain something else such as health information from pamphlets or other written documents, the person could use the "literacy services" of another member of the family. "Proximate" literacy, in this case, is as important as "individual" literacy. It follows that "literate household members generate a positive externality or a kind of public good for illiterate members" (Basu and Foster 1998: 1734, emphasis in original). To incorporate the externality generated by the education of other household members, the authors have further divided the illiterate persons in isolated illiterate (those that do not live with other literate people) and proximate illiterate (those living with at least one other literate person).

Based on the above arguments, some scholars have examined the effect of proximate literacy on outcomes such as the adoption of modern farm practices (Green, Rich, and Nesman 1985), farm productivity (Foster and Rosenzweig 1996), and women's earnings (Basu, Narayan, and Ravaillon 2002). Few studies have accounted for the potential externalities of literacy/education of household members different from the parents in improving children's nutritional and health status. Using community data for Papua New Guinea, Gibson (2001) finds that the proportion of proximate illiterate added to a model incorporating the standard adult literacy rate - has a significant effect on the average standardized height of young children, providing evidence that children of illiterate mothers can still benefit from the literacy services of other adults in the house. Using 1997 data from Mozambique and a different model specification, Lindelow (2008) finds that the effect of the education of the (non-parent) household 
member with the highest grade completed is higher than the effect of father's education, though statistically significant only for some of the employed indicators of child health. Finally, Moestue and Huttly (2008) conclude that grandmother's education affects children's nutritional levels in India (and not in Vietnam) and its effect is both direct (through childcare) and indirect (through modifying the effect of maternal education).

One subgroup in this field of study focuses on educational externalities at the community level. The basic assumption is that, in the context of developing countries, neighbors within a community can provide their literacy services to uneducated people, thus limiting the problems of individual illiteracy and affecting child nutrition. However, the empirical findings do not seem to provide robust evidence of this hypothesis (Desai and Alva 1998; Gibson 2001; Alderman, Hentschel, and Sabates 2003; Moestue and Huttly 2008).

Thus far this paper has focused on general children's nutrition. However, a distinction must be made between long-run and short-run nutritional status. As pointed out in detail in section four, the former is usually measured by the height-for-age Zscore (HAZ) or child stunting variable (binary variable indicating low HAZ), and the latter is determined by the weight-for-height Z-score (WHZ) or child wasting variable (binary variable indicating low WHZ). Finally, the weight-for-age Z-score (WAZ) or child underweight variable (binary variable indicating low WAZ) reflects either shortrun malnutrition, long-run malnutrition, or a combination of both.

The empirical literature shows that the determinants of the three phenomena may be different and particularly that parents' schooling and other socio-economic factors are more likely to have a larger effect on child HAZ than WHZ (Haddad et al. 2003; Miller and Rodgers 2009). For example, when looking at twelve low-income countries, Haddad et al. (2003) concluded that parents' education has a significant influence on child WHZ in only four countries. Among the few exceptions, Penders, Staatz, and Tefft (2000) reported a lower influence of mother's schooling on child HAZ in Mali. The evidence is much weaker when we compare the effects of mother's education on child height and weight. Some studies, in fact, show a positive and significant effect of this explanatory variable on both the outcomes (Morales, Aguilar, and Calzadilla 2004; Moestue and Huttly 2008). In particular, the work of Moestue and Huttly (2008: 156) suggests that the overall household education effects were similar for HAZ and WAZ, meaning that education operates "over the medium to longer term".

The theoretical explanation for the different role that socio-economic characteristics play for transitory and chronic malnutrition lies in the fact that the former is heavily influenced by short term events such as epidemics and famines, which are likely to hit most of the socio-economic groups. Genetic factors such as mother's anthropometrics affect acute malnutrition only up to a certain extent. Similarly, "mother's education is of limited effectiveness in preventing illness such as diarrhea" 
during epidemics and therefore also in combating short-run malnutrition (Miller and Rodgers 2009: 157). In contrast, factors like parents' education and household wealth play a vital role in the long-run nutritional status of children.

\section{Methodology}

The paper is an empirical study of the effects of household education on child height and weight. Both children's outcomes are modeled as a function of a list of child, mother, father, household, and regional level variables (full list in section 4). Household education is represented here by three distinguished variables: in addition to the commonly considered variable reflecting mother's education, we included one reflecting father's education and one reflecting the education/literacy of other household members. Father's schooling is important because mothers could use the "literacy services" of the husband and improve child nutrition. By controlling for this variable we can see whether the contribution of mother's education is independent from that of father's education.

In accordance with the literature on educational externalities, it is argued that neglecting other household members' education does not allow us to consider that an illiterate mother can benefit from the services of a literate household member; i.e., this would neglect the spillover effects from a literate to an illiterate person which is particularly crucial when the mother is the care taker. Another important reason to include this information is that other household members can play an active role as care-takers. In countries like Mozambique, the older sister or the grandmother are more likely than the father to spend time at home with the child and to cook for her/him.

While this paper incorporates the possibility of educational externalities within the household because it assumes that literate household members are "altruistic" - offering their literacy services freely - it does not consider potential externalities at the community level. We share the concerns of Basu and Foster (1998) and Gibson (2001) that, with the increase of the "relational distance" from the illiterate person, literate community members will charge a fee for their services, and a market will open up for these services. ${ }^{3}$

\footnotetext{
${ }^{3}$ In countries like Mozambique, sometimes we have extended families with several components. Members with distant relationship from the household head are somewhere between close family members and other members of the community. Thus, it is not easy to formulate a hypothesis regarding whether they would eventually provide literacy services free of charge or not. In household datasets like those used in this study, we cannot verify the exact relationship of each household member to the household head. Therefore, we assume that they are not paid for this activity.
} 
The econometric strategy consists of the estimation of two models, one with and one without the literacy of non-parental household members. In this way, we can examine whether the significance and the size of the effect of mother's schooling changes. These two steps are followed for both measures of children's nutritional status.

The estimates were carried out using Stata software, version 11 (STATA Corp., College Station, Texas). We employed the ordinary least square (OLS) estimator. While this choice can lead to biases due to the potential endogeneity of some explanatory variables (see Behrman and Deolalikar 1988), we believe that this problem is of secondary importance given the specific objectives of the paper. The paper, in fact, does not intend to identify the magnitude of the effect of education-related variables and does not aim at examining the channels through which this set of variables can influence children's nutritional status.

We also acknowledge the potential problems of multicollinearity given, for example, the simultaneous presence of regressors like household size and number of non-parental literate people (Gibson 2001). For this purpose, we run the variance inflation factor (VIF) ${ }^{4}$, which shows no multicollinearity bias in the several models estimated. Finally, we used the White robust standard errors since heteroskedasticity was detected in the initial models.

Finally, the last step of the empirical analysis compares the results obtained for the two nutritional indicators. While the health and nutrition literature suggests a strong difference between the determinants of child HAZ and child WHZ, corroborated by empirical evidence, this is not the case when we replace the latter with child WAZ. WAZ is affected by both short- and long-run factors. Thus, the assumption holds that the determinants may be the same, with the relative effects changing.

Only Morales, Aguilar, and Calzadilla (2004) have formally tested whether these factors provide a statistically significant contribution to these two outcome variables. We follow the same methodology - the seemingly unrelated regression - to verify this assumption in the case of Mozambique. Afterwards, a traditional test for equality of coefficients will be run in order to find out if the influence of the most important predictors is statistically different for the two phenomena. Based on previous studies and on the theoretical arguments discussed in the previous section, we expect parents' education and household wealth to have a similar or higher effect on child height-forage than on weight-for-age.

\footnotetext{
${ }^{4}$ The VIF is an index measuring how much variance of a regression coefficient is increased due to collinearity.
} 


\section{Dataset and data description}

This paper uses DHS data from the 2003 survey in sample areas of Mozambique. The final sample consists of 6,876 children from 0-5 years old who were alive at the time of the survey. In the following sub-sections, all the variables used in the study are presented.

\subsection{Measures of child nutrition}

We measured children's nutritional status with their height-for-age Z-score (HAZ) and weight-for-age Z-score (WAZ). The Z-score is adjusted for child's sex and age and measures (in standard deviations) how close the child is to the median value of the World Health Organization (WHO) reference population (WHO 1995). ${ }^{5}$ A child is considered "moderately malnourished" when her/his Z-score is minus two or below, and "severely malnourished" when it is minus three or below.

We argue that anthropometric measures such as height-for-age and weight-for-age better reflect children's nutritional conditions. While traditional calorie-based indicators assume that each individual (depending solely on their sex and age) should have a minimum amount of calories per day to survive and have an active life, the anthropometric indicators account for body heterogeneity. By focusing on subject's "symptoms", anthropometric indicators are more people-centered measures of malnutrition.

In particular, height-for-age reflects the accumulation of past outcomes and thus is a measure of chronic nutritional status while weight-for-age, an indicator used among others by UNICEF, is a measure of both chronic and acute nutritional status (Svedberg 2002).

\subsection{Explanatory variables}

Among the other characteristics analyzed in this study, child's sex and child's age were included as well. Though child HAZ and WAZ incorporate age and sex differentials, these variables can reflect gender-related and age-related influence of non-observed covariates on nutrition (Morales, Aguilar, and Calzadilla 2004). Many studies noticed

\footnotetext{
${ }^{5}$ This paper uses the 1995 reference population rather than the most recent dataset (WHO 2006), which is more appropriate to this study since most of the children of our sample have been breastfed. This is because the Z-scores based on the new growth standards were not available in the DHS dataset when we started working on this paper.
} 
that the anthropometry of younger children can be different from that of older children (Sahn and Alderman 1997). The age effect is analyzed with one dummy variable indicating whether the child is in the 25-60 month age group, as opposed to 0-24 months: this is because 24 months is a common breastfeeding duration in Africa.

The birth order placement of the child is an important variable since it can reveal parents' choices over allocation of resources (Horton 1988; Rubalcava and Contreras 2000). Based on past evidence, we expect the nutritional status of first children to be better than that of last children. Another independent variable is mother's age in years. Two variables were selected for mother's nutrition: simple height in centimeters and body mass index, which is calculated by her weight in kilograms divided by the square of her height in meters. ${ }^{6}$ Women with a BMI of 18.5 or lower are considered malnourished. These variables were measured during the 2003 survey and are treated as proxies for mother's nutrition during pregnancy.

Mother's and father's education are measured by their years of schooling. Regarding household, the models contain three variables: the first two are related to household size (number of components) and structure (proportion of $0-5$ aged members), while the third one is household wealth, which deserves a deeper explanation. DHS surveys do not contain information on household consumption or expenditures though there is plenty of information on different types of assets. The main reasons for this data exclusion are that consumption or expenditure estimations in low-income countries are not always reliable and an asset-based measure of wealth better reflects the permanent economic status of the household (Rutstein and Johnson 2004; Wall and Johnston 2008). Some authors have also shown that a wealth index might perform better particularly in explaining children's outcomes (Filmer and Pritchett 1999).

The DHS computes the wealth index by applying the principal components technique on qualitative variables - such as the type of flooring; ownership of land, car, bicycle, or refrigerator; and the use of public utilities (like water, public well, and public sewerages) and on a quantitative variable - number of rooms - adjusted for household size and age. After performing the principal component analysis, each household is assigned a standardized score for each asset, depending on whether or not the household owns that asset or on the number of people per room. The final household wealth index, obtained by summing all the indicator values, is a standardized score with the mean equal to zero and standard deviation equal to one. This index

\footnotetext{
${ }^{6}$ We are aware of the methodological problems related to the inclusion of mother's body mass index as explanatory variable of child anthropometry. This variable can be endogenous since it can be itself an outcome of, or a proxy for, household economic situation and the conditions of the living environment. However, after an in-depth sensitivity analysis we have concluded that this variable does not cause a substantial bias in the estimates and contributes to improve the explanatory power of the model (measured by the R-squared), and does not influence significance and size of the effect of the variables of interest.
} 
measures the wealth of a household as compared to the wealth of the average Mozambican household.

In order to account for possible literacy services of other members of the household, we included a regressor indicating whether at least one household member excluding mothers and fathers - is literate. ${ }^{7}$ Due to data constraints, a person is assumed to be literate if she/he has at least completed primary school. One further variable indicates whether the mother or someone else is taking care of the child. ${ }^{8}$ Controlling for this variable, we can better understand the effect of education-related variables.

\subsection{Descriptive statistics}

Table 1 presents descriptive statistics. The chronic nutritional status of children (HAZ) is very diverse, ranging from a minimum value far below the threshold for severe stunting (-6) to an extremely high value (4.78). The mean value, -1.679 , shows a large distance of the average Mozambican child from the reference population. Looking at child WAZ, children are closer to the average of the reference population, with a mean of -1.112 , but there is again a high variability, and this value shows that the nutritional level of the population is poor overall.

Our sample is almost equally representative of children less than two years old and between two and five years old and of boys and girls. With regard to mothers, we notice that their average age at the time of the survey is 28 . The educational levels of both parents are low, but fathers have completed almost double the number of years of schooling than mothers.

The mean value of household wealth is -0.127 . Since the final value of this index is a result of a standardization procedure applied to the whole households' sample, a negative mean indicates that the sample of households with children below five years of age is relatively poorer than the full households' sample. Finally, less than one family out of four has at least one further household member who is literate.

\footnotetext{
${ }^{7}$ We decided not to focus on other characteristics of these additional household members for three main reasons: 1) we have only little information; 2) we already have variables that provide some information on these components; namely, household size, the proportion of household members below five years of age, and household wealth in addition to the proximate literacy indicator; 3 ) this would increase the endogeneity bias in the model. The objective is to verify whether the literacy of at least another household member plays an additional role, or partly replaces the role of parents' education. Having included the above household-level variables, the effect of the covariate should not be overestimated.

${ }^{8}$ Excluding the mother, the person taking care of the child is, in order of frequency, the oldest sister (18.5\%), other relatives $(15.2 \%)$, the oldest brother $(8 \%)$, the neighbors $(1.55 \%)$, or the father $(0.7 \%)$. In the remaining cases it is either a friend or domestic help taking care of the child.
} 
Table 1: Descriptive statistics (unit of analysis: 0-5 year old children)

\begin{tabular}{|c|c|c|c|c|}
\hline & Mean & St. Dev. & Min. & Max. \\
\hline Child height-for-age Z-score (HAZ) & -1.679 & 1.416 & -6 & 4.78 \\
\hline Child weight-for-age Z-score (WAZ) & -1.112 & 1.230 & -5.93 & 4.53 \\
\hline Child age: dummy $25-60$ months & 0.544 & 0.498 & 0 & 1 \\
\hline Child's sex ( $1=$ female) & 0.502 & 0.500 & 0 & 1 \\
\hline Child's birth order number & 3.827 & 2.442 & 1 & 15 \\
\hline Mother's current age (in years) & 28.692 & 7.198 & 15 & 49 \\
\hline Mother's height (in $\mathrm{cm}$ ) & 155.483 & 6.056 & 132 & 188.9 \\
\hline Mother's body mass index & 22.027 & 3.059 & 13.15 & 49.76 \\
\hline Mother's years of schooling & 2.179 & 2.623 & 0 & 17 \\
\hline Father's years of schooling & 3.959 & 3.184 & 0 & 19 \\
\hline Household size & 7.070 & 3.518 & 2 & 30 \\
\hline $\begin{array}{l}\text { Proportion of household members in the } \\
\text { age group } 0-5\end{array}$ & 0.325 & 0.122 & 0.067 & 0.75 \\
\hline Household wealth (z-score) & -0.136 & 0.837 & -0.756 & 4.715 \\
\hline At least another $\mathrm{HH}$ member is literate & 0.229 & 0.421 & 0 & 1 \\
\hline The mother is the main care-taker ${ }^{a}$ & 0.531 & 0.499 & 0 & 1 \\
\hline
\end{tabular}

Notes: Sample size $=6,876$. ${ }^{a}$ For this variable the sample size is 5,553 .

Source: Our elaborations on Demographic and Health Survey, Mozambique 2003.

\section{Econometric estimates}

This section considers the results of different models. The models in section 5.1 aimed to study the determinants of child HAZ, while those in section 5.2 focused on the determinants of child WAZ. Finally, in section 5.3 results are compared.

\subsection{Determinants of child height-for-age}

Table 2 presents the estimates of the determinants of children's long-term nutritional status. In model (a), mother's schooling is highly significant which indicates that children whose mothers have higher educational attainments are likely to be taller than children whose mothers have fewer years of education. Another relevant variable for this study, father's years of schooling, is largely significant and positively correlated with child HAZ. As expected, household economic conditions have a positive impact, too.

In model (b), we add proximate literacy measures to account for possible externalities provided by literate members of the households different from the 
children's parents. The variable has a statistically significant effect on child HAZ at 5\% level, and does not capture a considerable proportion of the effect of parents' schooling. Furthermore, while their education can contribute to child nutrition by augmenting household economic resources, the fact that this variable is significant also after controlling for household wealth seems to indicate that the covariate operates also through other channels.

These results are in line with those of Lindelow (2008). ${ }^{9}$ Therefore, as argued by Gibson (2001), this variable plays a relevant role in child nutrition production and should not be omitted in these models. What is not clear is whether we can define it as externality. Applying the economic concept of externality in this field would mean that people different from the mother (or, eventually, the father) provide, free of charge, literacy services that affect child's nutrition, though they do not have a role in child care. The assumptions that child care is, by nature, left to mothers and that other household members' "education decisions do not take into account broader household effects on health care choices" (Lindelow 2008: 581, note 1) are controversial, and the same DHS data highlight that in about $46 \%$ of the Mozambican households, people other than parents are the primary care-givers.

For the above reasons, in model (c) we control for whether it is the mother or someone else in the family taking care of the child. Unfortunately, this variable is available for a lower number of observations $(5,416$ vs. 6,876$)$, thus the model could suffer from several biases. We notice a non-significant effect of this covariate, while the influence of a mother's education and other household members' literacy remains stable. This seems to suggest that the education of all family members is relevant regardless of who is the person responsible for the child.

In order to check whether parents' schooling operates in a similar way in households with and without illiterate members, two interaction terms were introduced. The results in model (d) show that the interaction with mother's schooling has a negative, but not significant, influence on child nutrition. The effect of mother's schooling is unchanged. This seems to suggest that the literacy of another household member plays an additional - though limited in quantitative terms - effect on child HAZ. Similarly, father's schooling, affects child long-run nutrition independently from the literacy of the other household members (model (e)).

\footnotetext{
${ }^{9}$ A straight comparison of the effect size of the education of other household members is not possible since Lindelow uses the highest grade completed as variable for proxy literacy and a binary variable for child nutrition.
} 
Table 2: Determinants of child height-for-age Z-score (HAZ) (0-5 years old)

\begin{tabular}{|c|c|c|c|c|c|}
\hline & (a) & (b) & (c) & (d) & (e) \\
\hline \multirow[t]{2}{*}{ Constant } & $-10.504^{* *}$ & $-10.505^{\star \star}$ & $-10.707^{\star \star}$ & $-10.490^{* *}$ & $-10.505^{\star \star \star}$ \\
\hline & $(0.441)$ & $(0.442)$ & $(0.499)$ & $(0.441)$ & $(0.442)$ \\
\hline \multirow[t]{2}{*}{ Child's age, $25-60$ months $^{a}$} & $-0.446^{* *}$ & $-0.446^{\star *}$ & $-0.440^{* *}$ & $-0.446^{* *}$ & $-0.446^{* *}$ \\
\hline & $(0.034)$ & $(0.034)$ & $(0.038)$ & $(0.034)$ & $(0.034)$ \\
\hline \multirow[t]{2}{*}{ Child's sex ${ }^{b}$} & $0.105^{* *}$ & $0.105^{*+}$ & $0.083^{*}$ & $0.105^{\star \star}$ & $0.105^{\star *}$ \\
\hline & $(0.032)$ & $(0.032)$ & $(0.036)$ & $(0.032)$ & $(0.032)$ \\
\hline \multirow[t]{2}{*}{ Child's birth order number } & -0.003 & -0.003 & -0.006 & -0.003 & -0.003 \\
\hline & $(0.012)$ & $(0.012)$ & $(0.012)$ & $(0.012)$ & $(0.012)$ \\
\hline \multirow[t]{2}{*}{ Mother's age (in years) } & 0.005 & 0.005 & 0.006 & 0.005 & 0.005 \\
\hline & $(0.004)$ & $(0.004)$ & $(0.004)$ & $(0.004)$ & $(0.004)$ \\
\hline \multirow[t]{2}{*}{ Mother's height } & $0.051^{* *}$ & $0.051^{* *}$ & $0.052^{* *}$ & $0.051^{* *}$ & $0.051^{\star \star}$ \\
\hline & $(0.003)$ & $(0.003)$ & $(0.003)$ & $(0.003)$ & $(0.003)$ \\
\hline \multirow[t]{2}{*}{ Mother's body mass index } & $0.040^{* *}$ & $0.040^{* *}$ & $0.038^{* *}$ & $0.040^{* *}$ & $0.040^{* *}$ \\
\hline & $(0.005)$ & $(0.005)$ & $(0.006)$ & $(0.005)$ & $(0.005)$ \\
\hline \multirow[t]{2}{*}{ Mother's years of schooling } & $0.025^{* *}$ & $0.023^{* t}$ & $0.027^{* \star}$ & $0.030^{* *}$ & $0.023^{* *}$ \\
\hline & $(0.008)$ & $(0.008)$ & $(0.009)$ & $(0.010)$ & $(0.008)$ \\
\hline \multirow[t]{2}{*}{ Father's years of schooling } & $0.021^{* *}$ & $0.016^{*}$ & 0.012 & $0.015^{*}$ & $0.018^{*}$ \\
\hline & $(0.006)$ & $(0.007)$ & $(0.008)$ & $(0.007)$ & $(0.008)$ \\
\hline \multirow[t]{2}{*}{ Household size } & $-0.010^{*}$ & $-0.010^{*}$ & $-0.013^{\star *}$ & $-0.010^{*}$ & $-0.010^{*}$ \\
\hline & $(0.005)$ & $(0.005)$ & $(0.005)$ & $(0.005)$ & $(0.005)$ \\
\hline \multirow[t]{2}{*}{ Prop. of HH members 0-5 y.o. } & 0.130 & 0.148 & 0.220 & 0.150 & 0.149 \\
\hline & $(0.148)$ & $(0.148)$ & $(0.168)$ & $(0.148)$ & $(0.148)$ \\
\hline \multirow[t]{2}{*}{ Household wealth (z-score) } & $0.194^{* *}$ & $0.184^{* *}$ & $0.154^{* *}$ & $0.191^{* \star}$ & $0.185^{* *}$ \\
\hline & $(0.024)$ & $(0.025)$ & $(0.031)$ & $(0.025)$ & $(0.025)$ \\
\hline \multirow{2}{*}{$\begin{array}{l}\text { At least one other } \mathrm{HH} \text { member is } \\
\text { literate }\end{array}$} & - & $0.097^{*}$ & $0.118^{*}$ & $0.160^{*}$ & 0.129 \\
\hline & & $(0.049)$ & $(0.057)$ & $(0.067)$ & $(0.094)$ \\
\hline \multirow[t]{2}{*}{ Mother is the main care-taker } & - & - & -0.053 & & \\
\hline & & & $(0.037)$ & & \\
\hline \multirow{2}{*}{$\begin{array}{l}\text { Mother's schooling * } \mathrm{HH} \text { member } \\
\text { literate }\end{array}$} & - & - & - & -0.019 & \\
\hline & & & & $(0.014)$ & \\
\hline \multirow{2}{*}{$\begin{array}{l}\text { Father's schooling * } \mathrm{HH} \text { member } \\
\text { literate }\end{array}$} & - & - & - & - & -0.005 \\
\hline & & & & & $(0.013)$ \\
\hline$\overline{\mathrm{N}}$ & 6876 & 6876 & 5416 & 6876 & 6876 \\
\hline adj. $R^{2}$ & 0.132 & 0.132 & 0.118 & 0.132 & 0.132 \\
\hline
\end{tabular}

Notes: White robust standard errors in parentheses.

${ }^{*} p<0.05,{ }^{* *} p<0.01$

${ }^{a}$ Reference: child age 0-24 months.

${ }^{\mathrm{b}}$ Reference: male.

Source: Our elaborations on Demographic and Health Survey, Mozambique 2003. 
Most of the other variables have a significant effect on child height. In particular, the height for age Z-score is significantly lower if children are in the 25-50 month agegroup. The dummy for gender of the child shows that girls have better nutritional levels than boys, which is consistent with the results of other studies in Sub-Saharan Africa (Svedberg 1990, 2002). ${ }^{10}$ Among the mother-level factors, as expected, mother's nutritional status plays a central role: both height-for-age and the body mass index are highly significant (p-value $<0.001$ ). In line with the majority of the other studies, the socio-economic status of the household has a positive effect on children's long-run nutrition.

\subsection{Determinants of child weight-for-age}

The overall variance explained by the determinants of child weight-for-age Z-score is lower than in the case of height, as indicated by the adjusted R-squared value (Table 3). Mother's schooling has a significant effect and its influence is independent from that of father's schooling, which is a very important predictor of child WAZ as well (column (a)).

With the inclusion of proximate literacy, only the effect of father's schooling slightly decreases (model (b)). Unlike the estimates of the determinants of child HAZ, the literacy services of other members of the household do not seem to improve child WAZ. As for other socio-economic factors, overall household education counts more for long-run undernutrition: specific health situations in the period preceding the survey are likely to be more important explanatory factors of child weight. As for child HAZ, the dummy variable indicating if the mother is the person taking care of the child is insignificant, and its inclusion does not substantially modify the coefficients of the education-related variables $(\operatorname{model}(\mathrm{c})) .{ }^{11}$

\footnotetext{
${ }^{10}$ For a different position on gender differences in anthropometric and mortality indicators in sub-Saharan Africa, see Klasen (1996).

${ }^{11}$ We remind the reader that these estimates are carried out on a limited number of observations, thus we cannot draw firm conclusions.
} 
Table 3: Determinants of child weight-for-age Z-score (WAZ) (0-5 years old)

\begin{tabular}{|c|c|c|c|c|c|}
\hline & (a) & (b) & (c) & (d) & (e) \\
\hline \multirow[t]{2}{*}{ Constant } & $-8.043^{\star \star}$ & $-8.043^{* *}$ & $-8.433^{* *}$ & $-8.015^{\star *}$ & $-8.043^{* *}$ \\
\hline & $(0.388)$ & $(0.388)$ & $(0.441)$ & $(0.387)$ & $(0.388)$ \\
\hline \multirow[t]{2}{*}{ Child's age, $25-60$ months $^{\text {a }}$} & $-0.218^{\star *}$ & $-0.218^{* *}$ & $-0.191^{* *}$ & $-0.218^{* *}$ & $-0.218^{* *}$ \\
\hline & $(0.030)$ & $(0.030)$ & $(0.034)$ & $(0.030)$ & $(0.030)$ \\
\hline \multirow[t]{2}{*}{ Child's sex ${ }^{b}$} & 0.046 & 0.046 & 0.022 & 0.047 & 0.045 \\
\hline & $(0.028)$ & $(0.028)$ & $(0.031)$ & $(0.028)$ & $(0.028)$ \\
\hline \multirow[t]{2}{*}{ Child's birth order number } & -0.010 & -0.010 & -0.013 & -0.011 & -0.010 \\
\hline & $(0.010)$ & $(0.010)$ & $(0.011)$ & $(0.010)$ & $(0.010)$ \\
\hline \multirow[t]{2}{*}{ Mother's age (in years) } & 0.004 & 0.004 & $0.008^{*}$ & 0.005 & 0.005 \\
\hline & $(0.003)$ & $(0.003)$ & $(0.004)$ & $(0.003)$ & $(0.003)$ \\
\hline \multirow[t]{2}{*}{ Mother's height } & $0.033^{* *}$ & $0.033^{* *}$ & $0.035^{* *}$ & $0.033^{* *}$ & $0.033^{* *}$ \\
\hline & $(0.002)$ & $(0.002)$ & $(0.003)$ & $(0.002)$ & $(0.002)$ \\
\hline \multirow[t]{2}{*}{ Mother's body mass index } & $0.074^{* \star}$ & $0.074^{* \star}$ & $0.079^{* \star}$ & $0.073^{* *}$ & $0.074^{* *}$ \\
\hline & $(0.005)$ & $(0.005)$ & $(0.005)$ & $(0.005)$ & $(0.005)$ \\
\hline \multirow[t]{2}{*}{ Mother's years of schooling } & $0.015^{\star}$ & $0.015^{\star}$ & $0.020^{*}$ & $0.030^{* *}$ & $0.015^{*}$ \\
\hline & $(0.007)$ & $(0.007)$ & $(0.009)$ & $(0.009)$ & $(0.007)$ \\
\hline \multirow[t]{2}{*}{ Father's years of schooling } & $0.016^{\star \star}$ & $0.016^{\star}$ & 0.012 & $0.014^{\star}$ & $0.022^{* *}$ \\
\hline & $(0.006)$ & $(0.006)$ & $(0.007)$ & $(0.006)$ & $(0.007)$ \\
\hline \multirow[t]{2}{*}{ Household size } & -0.003 & -0.003 & -0.006 & -0.004 & -0.004 \\
\hline & $(0.004)$ & $(0.004)$ & $(0.004)$ & $(0.004)$ & $(0.004)$ \\
\hline \multirow[t]{2}{*}{ Prop. of $\mathrm{HH}$ members $0-5$ y.o. } & 0.161 & 0.163 & 0.184 & 0.168 & 0.170 \\
\hline & $(0.129)$ & $(0.130)$ & $(0.146)$ & $(0.130)$ & $(0.130)$ \\
\hline \multirow[t]{2}{*}{ Household wealth (z-score) } & $0.152^{* *}$ & $0.151^{* \star}$ & $0.097^{* \star}$ & $0.166^{* \star}$ & $0.158^{* *}$ \\
\hline & $(0.023)$ & $(0.023)$ & $(0.029)$ & $(0.023)$ & $(0.023)$ \\
\hline \multirow{2}{*}{$\begin{array}{l}\text { At least another } \mathrm{HH} \text { member is } \\
\text { literate }\end{array}$} & & 0.012 & 0.009 & $0.137^{\star}$ & 0.142 \\
\hline & - & $(0.044)$ & $(0.051)$ & $(0.059)$ & $(0.088)$ \\
\hline \multirow[t]{2}{*}{ Mother is the main care-taker } & - & - & 0.003 & - & - \\
\hline & & & $(0.032)$ & & \\
\hline \multirow{2}{*}{$\begin{array}{l}\text { Mother's schooling * HH member } \\
\text { literate }\end{array}$} & & & & $-0.039^{* *}$ & \\
\hline & - & - & - & $(0.013)$ & - \\
\hline \multirow{2}{*}{$\begin{array}{l}\text { Father's schooling * } \mathrm{HH} \text { member } \\
\text { literate }\end{array}$} & & & & & -0.022 \\
\hline & - & - & - & - & $(0.012)$ \\
\hline $\mathrm{N}$ & 6876 & 6876 & 5416 & 6876 & 6876 \\
\hline adj. $R^{2}$ & 0.116 & 0.116 & 0.102 & 0.117 & 0.117 \\
\hline
\end{tabular}

Notes: White robust standard errors in parentheses.

${ }^{*} p<0.05,{ }^{* *} p<0.01$

${ }^{\text {a }}$ Reference: child age 0-24 months.

${ }^{\mathrm{b}}$ Reference: male.

Source: our elaborations on Demographic and Health Survey, Mozambique 2003. 
The interaction between mother's schooling and proximate literacy is negatively associated with child WAZ, leading to the conclusion that the contribution of mother's schooling to child nutrition is lower when another, non-father, household member is literate (column (d)). Therefore, unlike for child HAZ, mother's education and proximate literacy seem to be substituting factors for the reduction of children's underweight. In contrast, the interaction between father's schooling and proximate literacy is non-significant (model (e)).

The coefficients of the other child-, mother- and household-level covariates have the expected sign, though in most of the cases they have a lower statistical significance than in the estimates of child HAZ.

\subsection{Comparing results}

Many results are common to the two groups of models presented. In particular, mother's and father's schooling as well as household wealth are key determinants of both child height and weight. The last crucial variable for the study is given by the dummy variable measuring the presence of at least another literate person in the household: their literacy services seem to positively affect child HAZ and not child WAZ.

We also attempted to test whether the different impacts of the covariates on child HAZ and WAZ are statistically significant. For this reason, we adopted the approach followed by Morales, Aguilar, and Calzadilla (2004) which consists of estimating the equations for child HAZ and WAZ simultaneously through a seemingly unrelated regression model and then running a Wald test of equality of coefficients in the models. This implies relaxing the (implicit) assumption previously made that the disturbance errors of the models (b) of Table 2 and 3 are uncorrelated. ${ }^{12}$ The results (Table 4) highlight that the effect of household wealth and parents' education is not statistically different in the two equations. Instead, proximate literacy has a statistically significant higher influence on child chronic nutrition.

The other relevant coefficients that differ significantly are those for mother's height and mother's body mass index. All these covariates have a statistically significant larger effect on child height than on child weight. These results are in line with previous empirical findings according to which some focal biological and socioeconomic variables improve child nutrition more in the long run.

\footnotetext{
${ }^{12}$ In other words, now we do not assume any more that the explanatory variables separately influence child HAZ and WAZ.
} 
Table 4: Tests of equality of coefficients in equations for child HAZ and WAZ $(0-5$ years old $)$ - selected variables

\begin{tabular}{lccc}
\hline $\begin{array}{l}\text { H0: Is the coefficient equal in the two equations? } \\
\text { Variable }\end{array}$ & $\mathbf{C h i}^{\mathbf{2}} \mathbf{( 1 )}$ & Prob.>Chi $\mathbf{~}^{\mathbf{( 1 )}}$ & $\begin{array}{c}\text { Equal coefficient? } \\
\text { (0.05 sig. level) }\end{array}$ \\
\hline Mother's height & 76.33 & 0.000 & NO \\
Mother's body mass index & 64.75 & 0.000 & NO \\
Mother's years of schooling & 1.630 & 0.202 & YES \\
Father's years of schooling & 0.020 & 0.895 & YES \\
Household wealth (z-score) & 2.770 & 0.096 & YES \\
At least another HH member is literate & 5.360 & 0.021 & NO \\
\hline
\end{tabular}

Source: Our elaborations on Demographic and Health Survey, Mozambique 2003.

\section{Conclusions}

The first objective of the paper was to analyze the effect of several socio-economic variables on child nutrition in Mozambique paying major attention to the role of household's education. Coherently with the whole literature in this area, the estimates show that household wealth plays a central role in enhancing the nutritional status of the child: ceteris paribus, having more economic resources permits purchasing a larger amount and higher-quality food, access to health services when they are not free, and owning a house with a safe water system.

Moreover, we provide additional empirical evidence that attending some years of primary school is fundamental for mothers aiming at improving their children's longrun and short-run anthropometric status. On average, one year of a mother's formal education increases their children's HAZ by nearly 0.025 . The coefficient size is in line with most other studies conducted in developing countries on this topic [e.g. Christiaensen and Alderman (2001) in Ethiopia; Webb and Block (2004) in Indonesia; Morales, Aguilar, and Calzadilla (2004) in Bolivia; Medrano, Rodriguez, and Villa (2008) in South Africa]. One additional year of schooling raises child WAZ by about 0.015. This effect is slightly below that found by Aslam and Kingdon (2010) in Pakistan. For both outcomes, father's schooling has a highly significant effect as well.

We also included an additional variable indicating whether at least one other adult in the family is literate to verify whether their literacy services contribute to child nutrition. In line with other works (Moestue and Huttly 2008; Lindelow 2008) our analysis shows that this covariate contributes to explaining child height-for-age, though its effect-size is limited. Households with at least one additional literate member have a nearly $0.1 \mathrm{Z}$-score increase compared to households without. However, we have some 
concerns defining these "educational externalities" since this would imply assuming that mothers or parents are the only care-givers, which is often not the case in Mozambique.

This work joins a very limited set of studies that have considered household's education beyond parents' education. These results, as well as those obtained in previous works, show that the choice of leaving out the education/literacy of other household members can be problematical because these covariates may provide a contribution in explaining children's anthropometric status. Nowadays, this choice is less understandable since many large datasets, like those released by DHS, are available and offer this type of information for most developing countries.

The second objective of the paper was to analyze and compare the relevance of different covariates for the height and the weight of preschool children; two different, though related, phenomena. Based on our estimates on Mozambique, we conclude that there is no statistically significant difference in the (positive) effect of parents' education and household wealth on the two outcomes. The presence of another literate adult in the household, instead, is far more important to improve child HAZ.

We believe that these results can contribute to our understanding of the determinants of different nutritional indicators of preschool children and may be of great use for policy design. This paper reinforces the awareness that policies aiming at increasing the income of the most vulnerable households - by, for example, enlarging their employment opportunities - are going to have an important impact on children's nutrition. In the long-run, educational policies also seem to be crucial. Through different channels ranging from nutrition knowledge, access to information, empowerment, and wealth creation, a household's cumulative education can enhance children's nutritional levels. Should further studies in other low-income countries obtain similar and possibly more robust results, the presence of a wider positive effect of education would justify further investment by governments and donors in this sector and a possibly different targeting of beneficiaries.

Finally, we hope that, in the next years, there will be a number of studies in developing countries other than Mozambique to verify whether there is substantial evidence of the positive effect of proximate literacy to children's nutritional status. In particular, it would be important to understand what the causal mechanisms are and whether we can refer to it as "externality" (i.e., mothers have sole responsibility for the child's care but make use of the literacy services of other members; or, conversely that the other household members are also responsible for child care and the quality of that care is related to their educational level). Further research could make use of the increasing - though still limited - availability of panel data. 


\section{Acknowledgments}

The author would like to thank Bernard Harris for helpful comments on previous versions of the paper. I am also indebted to the Associate Editor Andrew Hinde and to two anonymous reviewers. 


\section{References}

Alderman, H., Hentschel, J., and Sabates, R. (2003). With the help of one's neighbors: Externalities in the production of nutrition in Peru. Social Science \& Medicine 56(10): 2019-2031. doi:10.1016/S0277-9536(02)00183-1.

Aslam, M. and Kingdon, G. (2010). Parental education and child health-Understanding the pathways of impact in Pakistan. Oxford: University of Oxford, Department of Economics (CSAE Working Paper Series 2010-16).

Barrera, A. (1990). The role of maternal schooling and its interaction with public health programs in child health production. Journal of Development Economics 32(1): 69-91. doi:10.1016/0304-3878(90)90052-D.

Basu, K. and Foster, J.E. (1998). On measuring literacy. Economic Journal 108(451): 1733-1749. doi:10.1111/1468-0297.00369.

Basu, K., Narayan, A., and Ravallion, M. (2001). Is literacy shared within households? Theory and evidence for Bangladesh. Labour Economics 8(6): 649-665. doi:10.1016/S0927-5371(01)00048-3.

Behrman, J.R. and Deolalikar, A.B. (1988). Health and Nutrition. In: Chenery, H. and Srinivasan, T.N. (eds.). Handbook of Development Economics (Vol. 1). Amsterdam: North Holland: 631-771. doi:10.1016/S1573-4471(88)01017-4.

Burchi, F. (2010). Child nutrition in Mozambique in 2003: The role of mother's schooling and nutrition knowledge. Economics \& Human Biology 8(3): 331-345. doi:10.1016/j.ehb.2010.05.010.

Christiaensen, L. and Alderman, H. (2001). Child malnutrition in Ethiopia: Can maternal knowledge augment the role of income? Washington, DC: World Bank (Africa Region Working Paper Series no. 22).

Desai, S. and Alva, S. (1998). Maternal education and child health: Is there a strong causal relationship? Demography 35(1): 71-81. doi:10.2307/3004028.

Filmer, D. and Pritchett, L. (2004). The effect of household wealth on educational attainment: Evidence from 35 countries. Population and Development Review 25(1): 85-120. doi:10.1111/j.1728-4457.1999.00085.x.

Food and Agriculture Organization (2006). The State of Food Insecurity in the World 2006. Rome: FAO. 
Foster, A.D. and Rosenzweig, M.R. (1996). Technical change and human-capital returns and investments: Evidence from the Green Revolution. American Economic Review 86(4): 931-953.

Frost, M.B., Forste, R., and Haas, D.W. (2005). Maternal education and child nutritional status in Bolivia: Finding the links. Social Science \& Medicine 60(2): 395-407. doi:10.1016/j.socscimed.2004.05.010.

Garrett, J.L. and Ruel, M.T. (1999). Are determinants of rural and urban food security and nutritional status different? Some insights from Mozambique. World Development 27(11): 1955-1975. doi:10.1016/S0305-750X(99)00091-1.

Gibson, J. (2001). Literacy and intrahousehold externalities. World Development 29(1): 155-166. doi:10.1016/S0305-750X(00)00082-6.

Glewwe, P. (1999). Why does mother's schooling raise child health in developing countries? Evidence from Morocco. Journal of Human Resources 34(1): 124-159. doi:10.2307/146305.

Green, S.E., Rich, T.A., and Nesman, E.G. (1985). Beyond individual literacy: The role of shared literacy for innovation in Guatemala. Human Organization 44(4): 313-321.

Haddad, L.J., Alderman, H., Appleton, S., Song, L., and Yohannes, Y. (2003). Reducing child malnutrition: How far does income growth take us? World Bank Economic Review 17(1): 107-131. doi:10.1093/wber/lhg012.

Horton, S. (1988). Birth order and child nutritional status: Evidence from the Philippines. Economic Development and Cultural Change 36(2): 341-354. doi:10.1086/451655.

Klasen, S. (1996). Nutrition, health and mortality in sub-Saharan Africa: Is there a gender bias? Journal of Development Studies 32(6): 913-932. doi:10.1080/ 00220389608422446.

Lindelow, M. (2008). Health as a family matter: Do intra-household education externalities matter for maternal and child health? Journal of Development Studies 44(4): 562-585. doi:10.1080/00220380801980905.

Medrano, P., Rodríguez, C., and Villa, E. (2008). Does mother's education matter in child's health? Evidence from South Africa. South African Journal of Economics 76(4): 612-627. doi:10.1111/j.1813-6982.2008.00210.x. 
Miller, J.E. and Rodgers, Y.V. (2009). Mother's education and children's nutritional status: New evidence from Cambodia. Asian Development Review 26(1): 131-165.

Moestue, H. and Huttly, S. (2008). Adult education and child nutrition: The role of family and community. Journal of Epidemiology \& Community Health 62(2): 153-159. doi:10.1136/jech.2006.058578.

Morales, R., Aguilar, A.M., and Calzadilla, A. (2004). Geography and culture matter for malnutrition in Bolivia. Economics \& Human Biology 2(3): 373-389. doi:10.1016/j.ehb.2004.10.007.

Penders, C.L., Staatz, J.M., and Tefft, J.F. (2000). How does agricultural development affect child nutrition in Mali? East Lansing: Michigan State University, Department of Agricultural Economics. (MSU Policy Synthesis No. 51).

Rubalcava, L. and Contreras, D. (2000). Does gender and birth order matter when parents specialize in child's nutrition? Evidence from Chile. Journal of Applied Economics 3(2): 353-386.

Rutstein, S.O. and Johnson, K. (2004). The DHS Wealth Index. Calverton MD: ORC Macro. (DHS Comparative Reports, No. 6.) http://www.measuredhs.com/ pubs/pdf/CR6/CR6.pdf

Sahn, D. and Alderman, H. (1997). On the determinants of nutrition in Mozambique: The importance of age-specific effects. World Development 25(4): 577-588. doi:10.1016/S0305-750X(96)00118-0.

Strauss, J. and Thomas, D. (1995). Human resources: Empirical modeling of household and family decisions. In: Behrman, J. and Srinivasan, T.N. (eds.). Handbook of Development Economics (Vol. 3). Amsterdam: North Holland: 1883-2023. doi:10.1016/S1573-4471(05)80006-3.

Svedberg, P. (1990). Undernutrition in sub-Saharan Africa: Is there a gender bias? Journal of Development Studies 26(3): 469-486. doi:10.1080/0022038900842 2165 .

Svedberg, P. (2002). Poverty and Undernutrition. New Delhi: Oxford University Press.

Thomas, D., Strauss, J., and Henriques, M.H. (1991). How does mother's education affect child height? Journal of Human Resources 26(2): 183-211. doi:10.2307/ 145920. 
United Nations Development Programme (2007). Human Development Report 2007. Fighting climate change: Human solidarity in a divided world. New York: United Nations.

Wall, M. and Johnston, D. (2008). Counting heads or counting televisions: Can assetbased measures of welfare assist policy-makers in Russia? Journal of Human Development 9(1): 131-147. doi:10.1080/14649880701811468.

Webb, P. and Block, S. (2004). Nutrition information and formal schooling as inputs to child nutrition. Economic Development and Cultural Change 52(4): 801-820. doi:10.1086/420901.

World Health Organization (1995). Physical status: The use and interpretation of anthropometry. Geneva: World Health Organization. (WHO Technical Report Series no. 854).

World Health Organization (2006). WHO Child Growth Standards: Length/Height-forAge, Weight-for-Age, Weight-for Length, Weight-for-Height and Body Mass Index-for-Age: Methods and Development. Geneva: WHO Multicentre Growth Reference Study Group. 
Burchi: Whose education affects a child's nutritional status? From parents' to household's education 